\title{
MINIMUM VARIANCE PORTFOLIOS IN THE GERMAN STOCK MARKET
}

\section{Jan Bastin*}

\begin{abstract}
The text demonstrates out-of-sample performances of minimum variance portfolios in the German stock market in the period 2002-2015. Because of two huge drawdowns on equity markets in the period 2000-2010, scholars and professionals have tried to find an alternative to the marketcap weighted investing; potentially the minimum variance investing approach. The paper presents the construction of minimum variance portfolios, the description of their compositions and empirical risk-return characteristics under various holding periods. As anticipated, minimum variance portfolios have lower risk vis-à-vis the CDAX index, but they have also higher returns. Finally, minimum variance portfolios have better risk-adjusted performance figures in comparison with equal-weighted alternatives.
\end{abstract}

Keywords: minimum variance portfolio, German stock market, CDAX index, risk minimization returns

JEL Classification: G11, G10

\section{Introduction}

The investment process has long been studied by academics and professionals. One of its parts is the portfolio construction activity. It was first demonstrated by Markowitz (1952) who formally showed relations between risks and returns in an optimization way. The result is the efficient frontier constructed by efficient portfolios. Those investment opportunities have maximum expected returns with a given level of risk or minimum variance of returns with a given level of portfolio yield. Portfolios which do not have those parameters are inefficient and dominated. Efficient portfolios are also called mean-variance portfolios and the efficient opportunity with the lowest risk is the minimum variance (volatility) portfolio. Other financial economists further improved the Markowitz's theory. Tobin (1958) and Sharpe (1964) added a risk-free asset which results in a linear efficient frontier - the Capital Market Line (CML). New efficient portfolios contain combinations of risky assets and the risk-free asset. The only efficient opportunity, which contains only risky assets, is the market portfolio. It both lies on the CML and the efficient frontier of Markowitz. With the development of Fama's Efficient Market Theory, many started to believe that a marketcap weighted portfolio (index) is a market portfolio and thus an efficient investment in the risk-return world. This resulted in launching index funds and ETFs by professionals in last decades.

* Jan Bastin, Faculty of Finance and Accounting, Department of Banking and Insurance, University of Economics in Prague, Prague, Czech Republic (xbasj08@vse.cz).

This paper was prepared with the support of the Internal Grant Agency (IG102024; "The Behavior of Prices of Investment and Credit Instruments"). 
The disappointing performance of market-cap weighted indices in the lost decade (2000-2010) forced investors and academics to think about an alternative investment approach. High volatility and two huge bear markets (the "dot.com bubble" and the financial crisis period) negatively impressed traditional index investors. Perhaps the renewal of the minimum variance concept is a potential solution. Due to the computational technology development, the portfolio optimization is today easily applicable in comparison with the period 50 years ago. The advantage of creating a minimum variance portfolio is the property that an investor does not need to forecast individual security returns. He is interested only in the risk minimization.

A pioneer analysis of the minimum variance strategy is described in Haugen and Baker (1991). Authors tried to measure the performance of the minimum variance portfolio. They argue that a market-cap weighted portfolio is efficient only if a set of assumptions is satisfied: all investors agree about the risk and the expected return for all securities; all investors can short-sell all securities; there are no taxes on security returns; an investment opportunity set for all investors holding any security in the index is restricted to the securities in the market-cap portfolio. Naturally, those conditions are very strong and probably not satisfied in reality. Authors created minimum variance portfolios from a population of 1000 of the largest stocks in the U.S. market for every quarter in the period 1972-1989. They concluded that the minimum variance portfolio had lower risk and same/higher return than the market-cap weighted portfolio (Wilshire 5000) and described the strategy of investing in a market-cap weighted index as an inefficient approach. Clarke, de Silva and Thorley (2006) improved the previous work by a longer period studied (1968-2005) and other methods of covariance matrix estimation. Their results are similar to Haugen and Baker. A different study, Jagannathan and Ma (2003), reported that a minimum variance portfolio out-of-sample performed better than other mean-variance portfolios if historical average returns are used as expected returns. Scherer (2010) studied minimum variance portfolio characteristics. He confirmed that minimum variance portfolios tend to have low beta and low volatility stocks. Others also documented characteristics of the minimum variance investing approach: Baker, Bradley and Wurgler (2011) measured and compared the minimum variance portfolio performance with characteristics of stocks sorted by volatility. Clarke, de Silva and Thorley (2011) wrote a paper about the minimum variance portfolio composition.

The text focuses on equities from the German stock market. The objective of the article is to construct minimum variance portfolios and report their empirical characteristics. We first describe the data and methodologies. Then, we demonstrate empirical results concerning minimum variance portfolios; and finally we discuss and conclude the text.

\section{Data and Methodology}

The analysis uses constituents of the CDAX index (a market cap weighted portfolio) which represents the German stock market. It includes all domestic companies listed in Prime Standard and General Standard, i.e. all firms listed on the Frankfurt Stock Exchange. The source of data is Bloomberg. The period studied is from March 2002 to March 2015. We use monthly total returns.

We apply the traditional model of Markowitz with additional constraints to create minimum variance portfolios. The variance of portfolio returns (proxy for risk) is minimized: 


$$
\sigma_{p}^{2}=\sum_{i=1}^{N} \sum_{j=1}^{N} \sigma_{i, j} w_{i} w_{j} \rightarrow \text { minimize }
$$

Where $\sigma_{p}^{2}$ is the variance of returns of portfolio $p, \sigma_{i, j}$ is the covariance between returns of asset $i$ and asset $j, w_{i}$ is the weight of asset $i$ in the portfolio and $N$ denotes the number of assets in the portfolio.

The variance is optimized without the need of individual security return estimation. In general, the portfolio yield is:

$$
R_{p}=\sum_{i=1}^{N} w_{i} r_{i}
$$

Where $R_{p}$ is the return of portfolio $p$ and $r_{i}$ is the return of asset $i$.

We assume some fixed constraints:

1. The maximum weight of an individual security in the portfolio is $5 \%$

2. The sum of weights of all stocks in the portfolio is $100 \%$

3. The maximum weight of an industry in the portfolio is $20 \%$

4. The minimum weight of an individual security is $0 \%$

It means that our minimum variance portfolios are fully invested in stocks and short sale opportunities are restricted. We create 3 minimum variance portfolios. The first one can invest in the top 200 stocks sorted by market capitalisation. The second one can invest in the top 100 stocks sorted by market cap; and finally the last one can invest only in the top 50 stocks sorted by market cap.

At the end of each quarter from March 2002 through December 2014, minimum variance portfolios are created. A stock can be selected in a portfolio if a set of conditions is satisfied: 1) It is a common stock; 2) It is a constituent of the CDAX index as of the formation date (end of quarter); 3) It has a history of returns for at least 60 months as of the formation date; 4) It is present in the top 200 (top 100 and top 50) stocks sorted by market cap as of the formation date. Conditions are specified for a reasonable comparison to the CDAX index, the estimation of a covariance matrix and to minimize the effect of look-ahead bias. It means that we estimate covariance matrices (52 quarters) with 60 months of historical return data. Due to the same number of stocks at the end of each quarter (top 200, top 100 and top 50), the number of elements in matrices does not change. Then we minimize (optimize) the risk function with estimated covariance matrices and our constraints. The optimizer quantifies weights of stocks. We repeat the optimization procedure as of the end of each quarter. Finally, portfolio returns are measured. If a stock disappears from the sample during a quarter (for example because of end of quotation on the exchange), we substitute its empty return fields by the average of returns of the industry the stock came from until the next formation date. Thus, we sort 200 highest market cap stocks in 10 industries and calculate average returns of industries each month. Because of a very low number of stocks in the Energy industry during the analysed period, we substitute its returns by the Utilities industry returns.

After the construction and performance measurement process, we can compare our minimum variance portfolios (MVP) to the market cap weighted CDAX. We also form equalweighted portfolios (for the top 200, the top 100 and the top 50 sorted by market cap) containing stocks satisfying requirements described above for an alternative comparison. This can be considered as a naive diversification approach. An empirical research provided by DeMiguel, Garlappi and Uppal (2009) concluded that a portfolio with an equal-weighted allocation was 
the best performer between 14 different strategies in the Sharpe ratio context. Below in the text, we present empirical characteristics of those equal-weighted investments (EWP).

We demonstrate returns with arithmetic and geometric averages. Standard Deviations and Betas are considered to be risk variables. Alphas and Sharpe ratios act as risk-adjusted performance figures. Alphas and betas are estimated with a classical regression equation used also by Jensen (1968):

$$
R_{p, t}-R_{f, t}=\alpha_{p}+\beta_{p}\left(R_{m, t}-R_{f, t}\right)+u_{p, t}
$$

Where $R_{p, t}$ is the portfolio return in time $t, R_{f, t}$ is the risk-free rate proxy (EURIBOR 1M Deposit) in time $t, R_{m, t}$ is the return of the market portfolio proxy (CDAX index or the EWP) in time $t, \alpha_{p}$ and $\beta_{p}$ are parameters to be estimated and $u_{p, t}$ are residuals. The classical t-ratio (t-statistic) is used to test the null hypothesis $\mathrm{H}_{0}: \alpha=0$. Finally, we also show cumulative returns throughout the whole period tested.

\section{Empirical Results}

Historical measures of minimum variance portfolios are presented in Table 1. We also show results of the CDAX index. Characteristics of equal-weighted portfolios are demonstrated in Table 2. In general, all selected portfolios are less risky than the CDAX index. They have lower standard deviations and betas in comparison with CDAX index measures. The volatility of the top $200 \mathrm{MVP}$ is about $60 \%$ lower than the standard deviation of the index. We measure two types of Betas and Alphas: The first one considers the CDAX (Beta (CDAX) and Alpha $(\mathrm{CDAX}))$ as the market proxy and the second type considers equal-weighted portfolios (Beta (EWP) and Alpha (EWP)) as the market proxies. The Beta (CDAX) parameters of all minimum variance portfolios are below 0.55 which indicates a huge reduction in systematic risk. All MVPs have higher returns and lower risk variables in comparison with the CDAX index. In the riskreturn context, it seems that the CDAX index is an inefficient investment opportunity. Highest Sharpe ratios were produced by MVPs. In the case of our minimum variance portfolios we reject the null hypothesis in alpha measures vis-à-vis the CDAX index. It means that the excess returns of our portfolios are significantly different from those of the CDAX index. We are able to reject the null in the case of the top 100 and top 50 MVPs, if we consider equal-weighted portfolios as market proxies. The highest cumulative returns were produced by the top 100 equal-weighted portfolio (321.6\%) and the lowest by the CDAX index (144.2\%). It means that equal-weighted alternatives are more profitable but also more risky. Despite of this fact their risk parameters are lower than those of the CDAX index. When CDAX returns are positive MVPs rarely outperform (only $13 \%$ of all positive return months for the top 200, 21\% for the top 100 and $32 \%$ for the top 50). In the case of negative index returns, the out-performance of MVPs is very strong. MVPs outperform in more than $85 \%$ of all negative return months.

We report year-by-year returns (measured from the end of March of year $Y$ to the end of March of year $Y+1$ ) in Table 3. All portfolios had negative returns in the bear market year 2008. Top 200 and top 100 MVPs outperformed the index in six out of thirteen years and the top 50 MVP out-performed the CDAX in nine out of thirteen years. Minimum variance portfolios had lower losses than the index in bear market periods (from March 2002 to March 2003, from March 2008 to March 2009 and from March 2011 to March 2012). Top 200 and top 50 MVPs report only two years of negative returns. This fact supports the idea that the CDAX is more risky, it out-performs MVPs in good times, but its losses in bad times are too high. Thus, the index is not able to have similar/higher returns in comparison with our MVPs. 
Table 1 | Historical Characteristics of Minimum Variance Portfolios in the Period 2002-2015

\begin{tabular}{|l|c|c|c|c|}
\hline & MVP (top 200) & MVP (top 100) & MVP (top 50) & CDAX \\
\hline Average Returns & $0.69 \%$ & $0.84 \%$ & $0.91 \%$ & $0.76 \%$ \\
\hline Geometric Average Returns & $0.66 \%$ & $0.80 \%$ & $0.84 \%$ & $5.97 \%$ \\
\hline Standard Deviation & $2.46 \%$ & $2.79 \%$ & $3.69 \%$ & 1.000 \\
\hline Beta (CDAX) & 0.286 & 0.353 & 0.548 & 0.102 \\
\hline Sharpe Ratio & 0.221 & 0.248 & 0.207 & - \\
\hline Alpha (CDAX) & $0.37 \%$ & $0.48 \%$ & $0.43 \%$ & - \\
\hline Alpha (t-stat.) & $2.543^{* *}$ & $3.198^{* * *}$ & $3.103^{* * *}$ & - \\
\hline Beta (EWP) & 0.442 & 0.506 & 0.670 & - \\
\hline Alpha (EWP) & $180.57 \%$ & $248.93 \%$ & $271.60 \%$ & $-2.20 \%$ \\
\hline Alpha (t-stat.) & $0.17 \%$ & $0.24 \%$ & $2.403^{* *}$ & - \\
\hline Cumulative Returns & 1.323 & & & - \\
\hline
\end{tabular}

Note: Alpha (t-stat.) is the t-statistic $\left({ }^{* * *},{ }^{* *},{ }^{*}\right.$ denote rejection of the null at the $1 \%, 5 \%$ and $10 \%$ level of significance)

Source: Own analysis.

Table 2 | Historical Characteristics of Equal-Weighted Portfolios in the Period 2002-2015

\begin{tabular}{|l|c|c|c|c|}
\hline & EWP (top 200) & EWP (top 100) & EW (top 50) & CDAX \\
\hline Average Returns & $1.00 \%$ & $1.04 \%$ & $0.86 \%$ & $0.76 \%$ \\
\hline Geometric Average Returns & $0.90 \%$ & $0.93 \%$ & $0.73 \%$ & $0.57 \%$ \\
\hline Standard Deviation & $4.39 \%$ & $4.69 \%$ & $5.06 \%$ & $5.98 \%$ \\
\hline Beta (CDAX) & 0.657 & 0.736 & 0.825 & 1.000 \\
\hline Sharpe Ratio & 0.193 & 0.189 & 0.141 & 0.102 \\
\hline Alpha (CDAX) & $0.45 \%$ & $0.44 \%$ & $0.21 \%$ & - \\
\hline Alpha (t-stat.) & $2.817^{* * *}$ & $3.320^{* * *}$ & $2.248^{* *}$ & - \\
\hline Cumulative Returns & $303.79 \%$ & $321.61 \%$ & $212.21 \%$ & $144.20 \%$ \\
\hline
\end{tabular}

Note: Alpha (t-stat.) is the t-statistic $\left({ }^{* * *},{ }^{* *},{ }^{*}\right.$ denote rejection of the null at the $1 \%, 5 \%$ and $10 \%$ level of significance)

Source: Own analysis. 
Table 3 | Year by Year Returns (in \%)

\begin{tabular}{|l|c|c|c|c|}
\hline Year & MVP (top 200) & MVP (top 100) & MVP (top 50) & CDAX \\
\hline $\mathbf{2 0 0 2}$ & 0.04 & -12.81 & -29.24 & -51.13 \\
\hline $\mathbf{2 0 0 3}$ & 19.56 & 24.73 & 23.92 & 59.15 \\
\hline $\mathbf{2 0 0 4}$ & 14.89 & 21.90 & 17.77 & 13.21 \\
\hline $\mathbf{2 0 0 5}$ & 24.60 & 32.27 & 40.49 & 39.76 \\
\hline $\mathbf{2 0 0 6}$ & 10.98 & 16.93 & 18.98 & 17.37 \\
\hline $\mathbf{2 0 0 7}$ & -9.03 & -10.89 & 0.95 & -7.09 \\
\hline $\mathbf{2 0 0 8}$ & -18.28 & -20.40 & -27.91 & -40.57 \\
\hline $\mathbf{2 0 0 9}$ & 12.13 & 25.48 & 43.08 & 53.49 \\
\hline $\mathbf{2 0 1 0}$ & 16.34 & 17.15 & 15.32 & 16.30 \\
\hline $\mathbf{2 0 1 1}$ & 4.08 & 5.00 & 3.30 & -1.74 \\
\hline $\mathbf{2 0 1 2}$ & 14.57 & 19.05 & 20.21 & 13.66 \\
\hline $\mathbf{2 0 1 3}$ & 12.33 & 12.28 & 11.79 & 23.09 \\
\hline $\mathbf{2 0 1 4}$ & 13.66 & 16.30 & 29.14 & 24.77 \\
\hline
\end{tabular}

Source: Own analysis.

Figure 1 is divided into two parts showing the comparison of realized rolling two years standard deviation of returns (calculated as 24 months trailing standard deviation) between portfolios and the CDAX index. All minimum variance portfolios had lower volatility risk throughout the period studied. The picture supports results in Table $1-$ minimum variance portfolios are less risky than the CDAX index. We also plot standard deviations of equalweighted alternatives.

Cumulative returns of our investment opportunities are demonstrated in Figure 2. We clearly see the effect of the optimization technique. Minimum variance portfolios did not have as wide fluctuations in returns as the index. The drawdowns in the financial crisis period were less painful for minimum variance portfolios. The top 200 MVP fell by $31 \%$, the top 100 MVP fell by 33\%, the top 50 MVP fell by $36 \%$ and a drawdown of $54 \%$ was measured for the CDAX index. Values of equal-weighted portfolios declined in a similar way (the top 200 EWP fell by $51 \%$, the top 100 EWP fell by 49\%, and the top 50 EWP fell by $50 \%$ ). Minimum variance and equal-weighted portfolios were able to cover losses from bad times earlier than the CDAX index. 
Figure 1 | 24 Months Trailing Standard Deviations of Portfolios
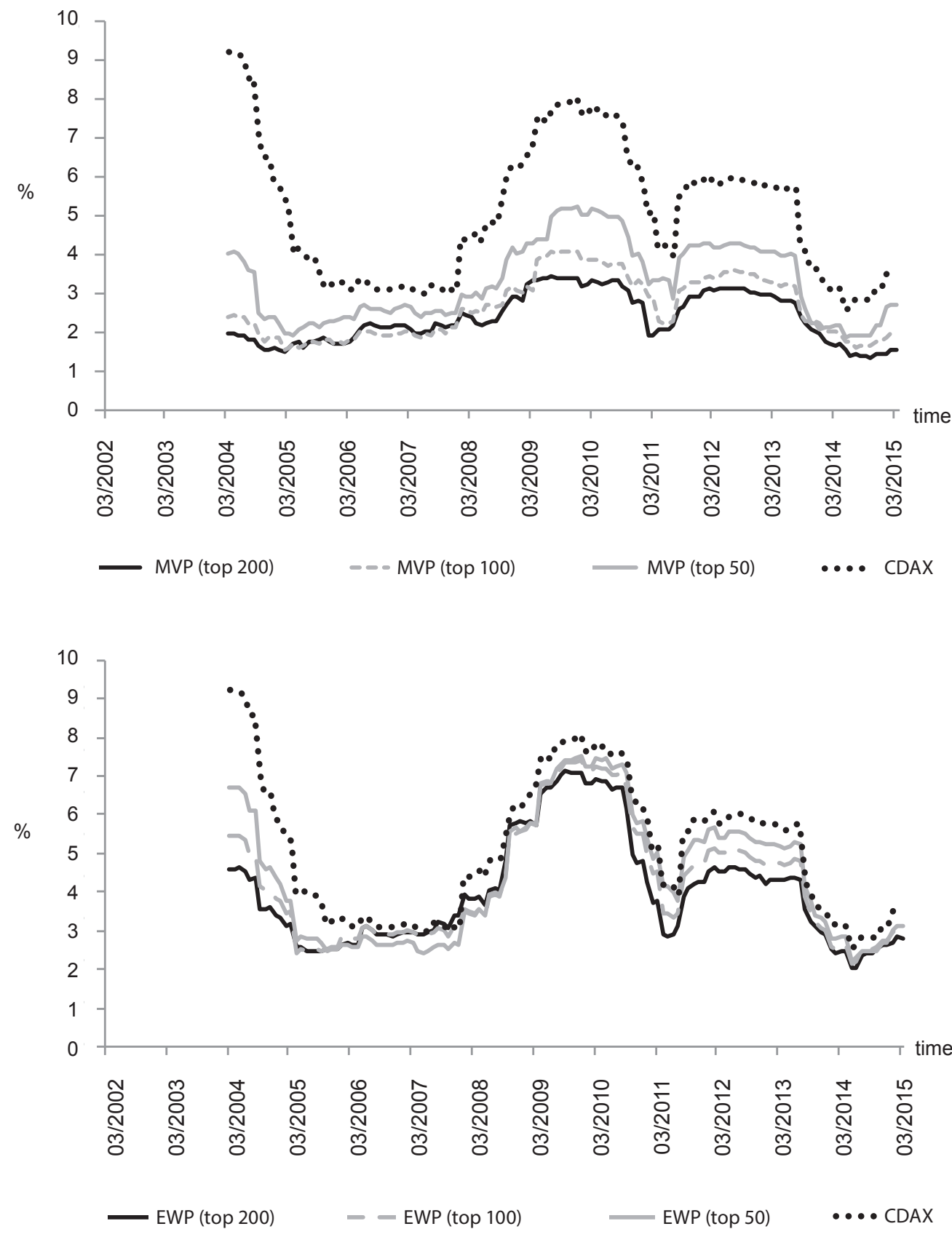

Source: Own analysis. 


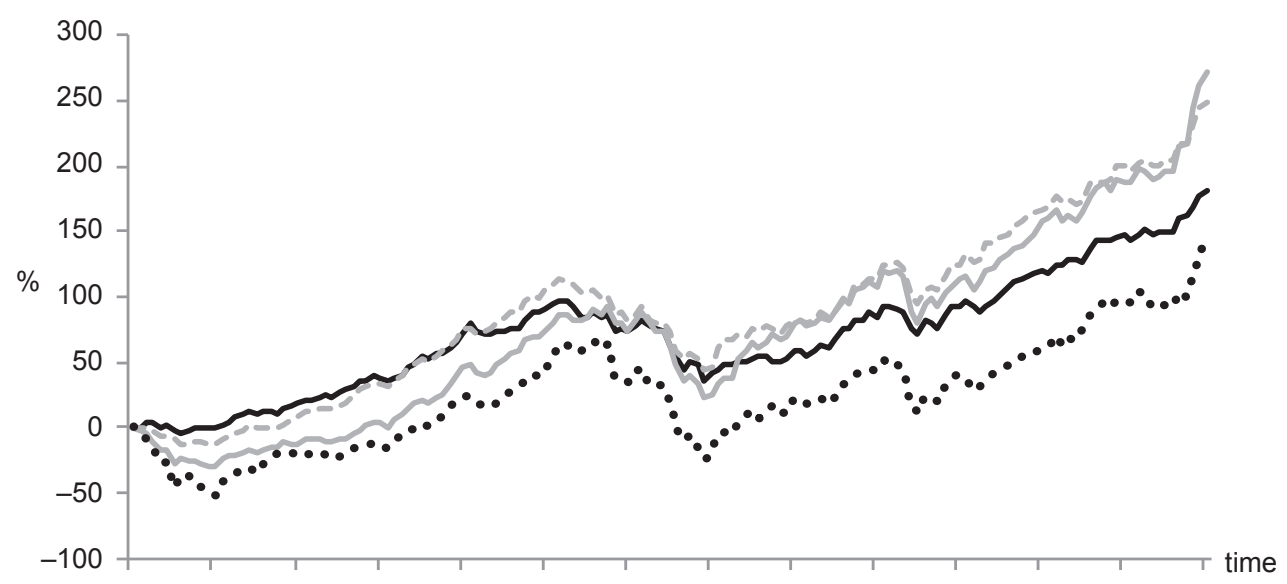

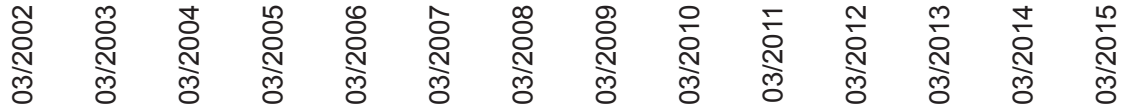
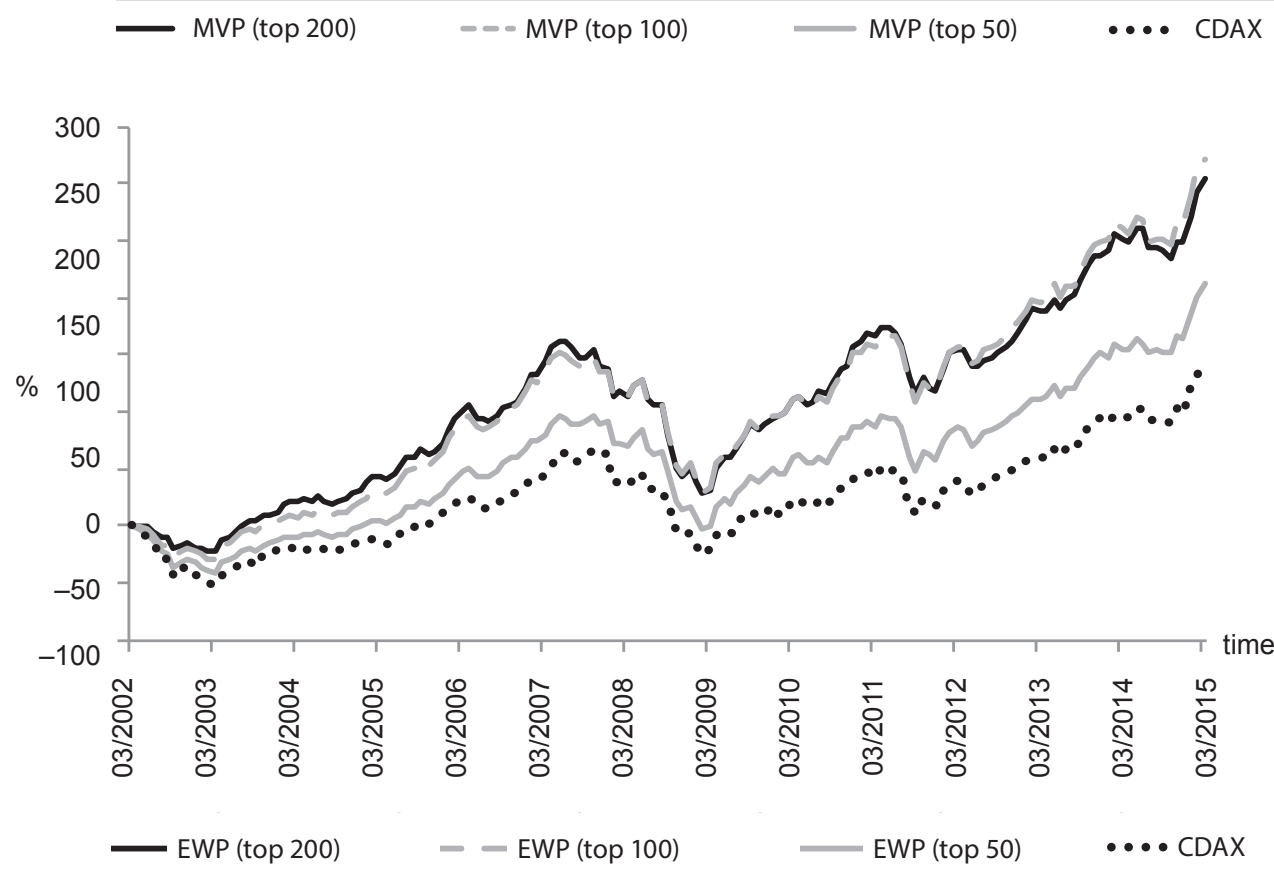

Source: Own analysis.

The next figure plots our basic results in the risk-return world. Again, it seems that the CDAX is dominated by our minimum variance and equal-weighted portfolios. According to the basic relation between risk and return in traditional financial theories, one can expect 
that an investment opportunity is more profitable if it is also more risky. The figure below does not confirm this interpretation. We can point that the analysed period contains both bull and bear markets. As a more risky investment opportunity, it performs worse in bad times which is not necessarily against the classical financial economics story.

Figure 3 | Portfolios in the Risk-Return Space

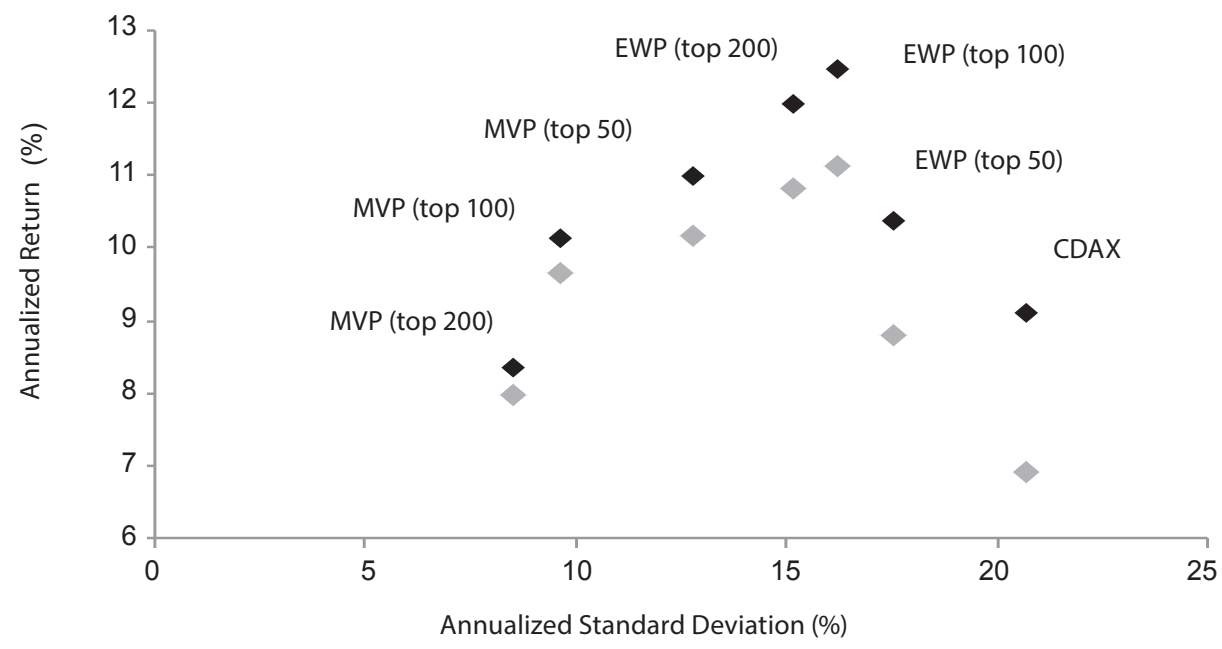

Average Return

Compound Return

Source: Own analysis.

\subsection{Industries in portfolios}

We divided stocks in ten industries. Thus, we can present figures concerning the composition of minimum variance portfolios. Average and median weights of industries are shown in the Table 4.

Due to the industry diversification constraint, the maximum weight of an industry cannot breach $20 \%$. On average, minimum variance portfolios have the biggest exposition towards stocks from Financial, Consumer and Utilities industries. One can see the lowest exposure in Diversified and Energy industries. Figure 4 shows cumulative weights of industries of the top 200 MVP. The portfolio is invested at least in 8 out of 10 industries in the analysed period (top 100 and top 50 MVPs are invested at least in 7 out of 10 industries). Thus, our investments are diversified in different industries. 
Table 4 | Average and Median Weights of Industries in Minimum Variance Portfolios (in \%)

\begin{tabular}{|l|c|c|c|c|c|c|}
\hline \multirow{2}{*}{} & \multicolumn{2}{|c|}{ MVP (top 200) } & \multicolumn{2}{c|}{ MVP (top 100) } & \multicolumn{2}{c|}{ MVP (top 50) } \\
\cline { 2 - 7 } & Average & Median & Average & Median & Average & Median \\
\hline Basic Materials & 7.08 & 6.56 & 9.84 & 9.67 & 12.57 & 13.08 \\
\hline Communications & 6.21 & 5.50 & 5.90 & 5.63 & 8.78 & 10.00 \\
\hline Consumer, Cyclical & 16.71 & 17.39 & 14.99 & 14.94 & 15.04 & 15.01 \\
\hline Consumer, Non-cyclical & 16.73 & 18.61 & 17.74 & 20.00 & 19.74 & 20.00 \\
\hline Diversified & 0.00 & 0.00 & 0.00 & 0.00 & 0.11 & 0.00 \\
\hline Energy & 1.23 & 0.00 & 0.19 & 0.00 & 0.96 & 0.00 \\
\hline Financial & 18.54 & 20.00 & 19.59 & 20.00 & 17.83 & 19.92 \\
\hline Industrial & 15.48 & 19.70 & 11.79 & 10.55 & 6.08 & 5.48 \\
\hline Technology & 5.22 & 1.42 & 2.28 & 0.16 & 2.79 & 0.15 \\
\hline Utilities & 12.78 & 12.22 & 17.67 & 20.00 & 16.09 & 20.00 \\
\hline
\end{tabular}

Source: Own analysis.

Figure 4 | Cumulative Weights of Industries in the MVP (top 200) in the Period 2002-2015

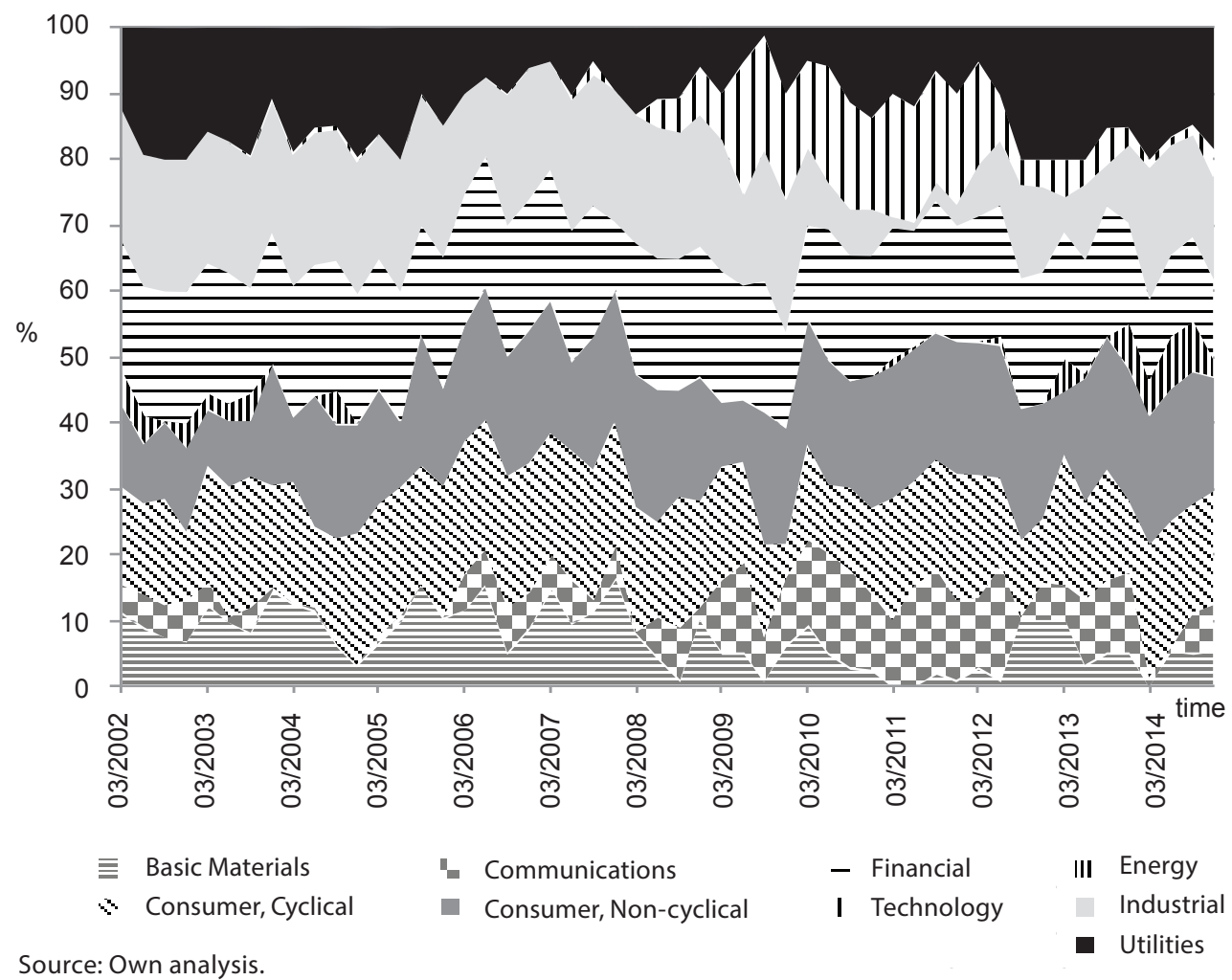




\subsection{Other holding periods}

Figure 5 demonstrates the number of stocks selected in minimum variance portfolios in the analysed period. The average number of stocks in the top 200 MVP is 107; the average in the top $100 \mathrm{MVP}$ is 49 and 28 stocks is the average in the top 50 MVP. We do not apply a turnover constraint. Thus, the number of securities sometimes changes widely from quarter to quarter. We now assume that investors have a longer holding period than one quarter. In reality, it means lower stock trading activity and trading fees.

Figure 5 | The Number of Stocks in Minimum Variance Portfolios in the Period 2002-2014

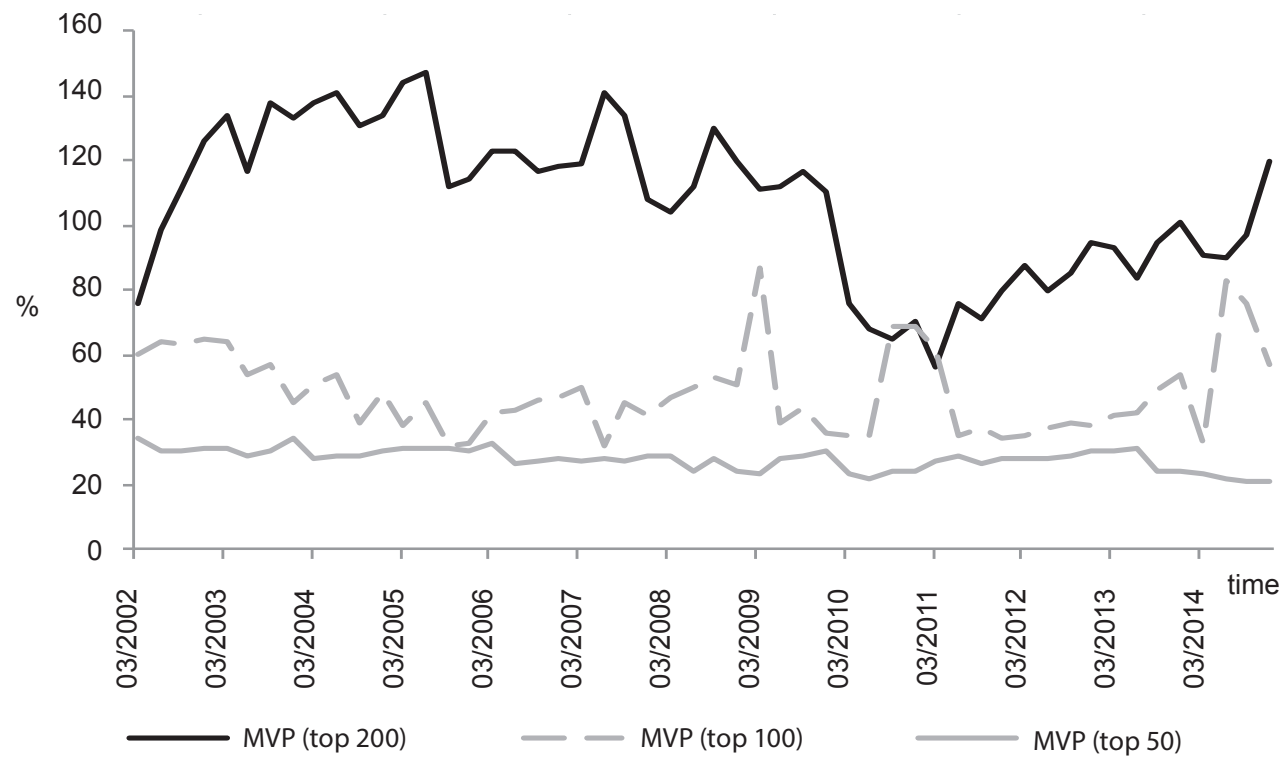

Source: Own analysis.

In the part of data and methodology description we pointed out that we launch the optimization at the end of every quarter. We also calculated other minimum variance portfolio performances in cases that the optimization is provided semi-annually (formation dates are ends of March and September) and annually (formation dates are ends of March). It simulates a situation where investors hold created portfolios for 6 or 12 months. Selected characteristics are reported in the Table 5.

The ability of results is similar to Table 1 . Highest average returns were produced by the top 100 MVP. The top 200 MVP opportunity has the lowest standard deviations for both 6 and 12 months of holding periods. All portfolios have higher average returns and lower risk parameters than the CDAX index. All Sharpe ratios are higher than the CDAX one. Top 200 and top 100 MVPs investments (both 6 and 12 months of holding periods) have higher Sharpe ratios than investments of the classical one quarter rebalancing frequency. Excess returns of all posted investments are statistically significantly different from excess returns 
of the CDAX index. If we consider equal-weighted alternatives ${ }^{1}$ as market portfolio proxies, alphas are statistically significant only in the top 100 case. Highest cumulative returns were also produced by the top $100 \mathrm{MVP}$ with 12 months of holding period. Unfortunately, we are not able to show the benefit of a longer holding period, which occurred in lower trading costs - we did not incorporate them in the analysis.

Table 5 | Empirical Characteristics and Different Holding Periods

\begin{tabular}{|l|c|c|c|c|c|c|}
\hline & \multicolumn{2}{|c|}{ MVP (top 200) } & \multicolumn{2}{c|}{ MVP (top 100) } & \multicolumn{2}{c|}{ MVP (top 50) } \\
\cline { 2 - 6 } & $\mathbf{6 M}$ & $\mathbf{1 2 M}$ & $\mathbf{6 M}$ & $\mathbf{1 2 M}$ & $\mathbf{6 M}$ & $\mathbf{1 2 M}$ \\
\hline Average Returns & $0.78 \%$ & $0.77 \%$ & $0.91 \%$ & $0.96 \%$ & $0.79 \%$ & $0.76 \%$ \\
\hline $\begin{array}{l}\text { Geometric Average } \\
\text { Returns }\end{array}$ & $0.74 \%$ & $0.73 \%$ & $0.87 \%$ & $0.91 \%$ & $0.73 \%$ & $0.69 \%$ \\
\hline Standard Deviation & $2.53 \%$ & $2.66 \%$ & $2.90 \%$ & $3.02 \%$ & $3.64 \%$ & $3.81 \%$ \\
\hline Beta (CDAX) & 0.280 & 0.296 & 0.372 & 0.399 & 0.543 & 0.573 \\
\hline Sharpe Ratio & 0.247 & 0.232 & 0.261 & 0.267 & 0.177 & 0.160 \\
\hline Alpha (CDAX) & $0.45 \%$ & $0.43 \%$ & $0.53 \%$ & $0.56 \%$ & $0.31 \%$ & $0.31 \%$ \\
\hline Alpha (t-stat.) & $2.934^{* * *}$ & $2.677^{* * *}$ & $3.492^{* * *}$ & $3.711^{* * *}$ & $2.329 * *$ & $2.329^{* *}$ \\
\hline Beta (EWP) & 0.460 & 0.489 & 0.542 & 0.585 & 0.662 & 0.709 \\
\hline Alpha (EWP) & $0.21 \%$ & $0.17 \%$ & $0.26 \%$ & $0.25 \%$ & $0.17 \%$ & $0.09 \%$ \\
\hline Alpha (t-stat.) & $1.692^{*}$ & 1.228 & $2.191^{* *}$ & $2.282^{* *}$ & 1.460 & 0.806 \\
\hline Cumulative Returns & $217.44 \%$ & $210.91 \%$ & $284.37 \%$ & $311.34 \%$ & $209.52 \%$ & $190.86 \%$ \\
\hline
\end{tabular}

Note: Alpha (t-stat.) is the t-statistic $\left(* * *,{ }^{* *},{ }^{*}\right.$ denote rejection of the null at the $1 \%, 5 \%$ and $10 \%$ level of significance)

Source: Own analysis.

\section{An Alternative Explanation}

Academic papers have documented better risk-return measures of minimum variance portfolios in comparison with market-cap weighted indices. What is the reason for this "pattern"? Scherer (2010) reported that $83 \%$ of the variation of minimum variance portfolio excess returns can be attributed to the Fama and French factors (see Fama and French, (1996)): value and size (Fama and French (1992) documented higher than average returns of value and small cap stocks) and risk factors (beta and volatility). This fact can be related to the "low risk anomaly" described in Ang, Hodrick, Xing and Zhang (2006), Blitz and van Vliet (2007), or Baker, Bradley and Wurgler (2011). These authors sorted stocks by different risk measures (residual risk, standard deviation or beta) and they demonstrated that low volatility and low beta stocks outperform high-risk stocks as well as the market proxy in the long-run with statistically significant results. Performances of low risk sorts/

1 We also assume different holding periods when constructing equal-weighted portfolios. 
portfolios cannot be explained by traditional financial theories. Ang, Hodrick, Xing and Zhang (2009) argued that low risk stocks tend to have lower analyst coverage and thus new information about those stocks are incorporated into prices more slowly. Baker and Haugen (2012) have an explanation concerning the investment process in asset management firms. Analysts tend to recommend popular stocks to their portfolio managers. This behaviour creates a demand by professional investors, which results in over-pricing of popular (volatile) stocks. Popular stocks are also more cited in financial media. Blitz and van Vliet (2007) argued that low volatility stocks are unattractive because of leverage restrictions. Baker, Bradley and Wurgler (2011) proposed a combined explanation. They showed two main drivers of the low-risk anomaly. The first one is the irrational behaviour of market participants. It seems that the preference for high-risk equities is influenced by behavioural biases. Authors demonstrated an examination of Preference for lotteries, Representativeness and Overconfidence biases. The second driver is related to the fact that investors used to manage portfolios relative to benchmarks. Baker et al. cited that $95 \%$ of U.S. mutual funds use a popular benchmark to manage their assets. The main objective of these professionals is to maximize the information ratio (the difference of expected returns of the portfolio and the benchmark divided by the tracking error). Authors mentioned that low-risk stocks have large tracking errors (unattractive IRs) in comparison with other "anomalies". Thus, benchmarking makes low-volatility shares to be a wrong bet for mutual funds.

If those reasons persist, the low-risk anomaly is likely to survive. And characteristics of minimum variance portfolios will probably continue to be attractive, too. There is a group of institutional investors which is able also to have attractive performance figures and their portfolios do not need to be benchmarked. Musílek and Jeřábek (2015) studied the impact of hedge funds behaviour on equity markets. They reported that hedge funds have lower risk and higher returns in comparison with main world indices. One can ask a question: Do hedge funds apply the minimum variance strategy? We do not have an adequate answer. Hedge funds can use a various sets of investment strategies. The market-neutral strategy ${ }^{2}$ can be related to the minimum variance approach, at least by working with a similar optimizing procedure used in our calculations. Investors would only reject the short-sale restriction, use leverage, and thus be able to construct a market-neutral portfolio, a beta-neutral portfolio or other "hedged" portfolios. Another idea can be applied: Buying low-risk stocks and shorting high-risk securities. An important problem occurs in back-testing the strategy when short sales are permitted. In reality, all stocks in the universe are not available to be shorted and there are also leverage restrictions.

For a comparison of our minimum variance portfolio strategy to the low-volatility anomaly, we create volatility quintiles. We work with the top 200 highest market cap equities. Thus, every quintile is invested in 40 stocks. At the end of every quarter, we sort stocks by their 60 months standard deviations and add them in 5 groups. Sort Q1 contains the lowest volatility stocks and the highest volatility stocks are in Q5 sort. Securities in quintiles are equal-weighted.

Empirical characteristics of quintiles are demonstrated in Table 6 which is posted in the same way as Table 1. The highest volatility stocks group has the lowest return results. Risk measures (standard deviations and both CDAX and EWP betas) grow from Q1 to Q5. Sharpe ratios decrease from the lowest volatility stocks to the highest volatility securities.

2 A combination of long and short positions in different securities. 
Except for Q5 group, all excess returns are statistically significantly different from CDAX excess returns. Q2 group has the highest cumulative returns. The top 200 MVP has lower returns, risks and also risk-adjusted performance results in comparison with Q1 group. Thus, the choice of agents to invest in the top $200 \mathrm{MVP}$ or the Q1 sort depends on their objectives. If they prefer the minimum risk profile, the top $200 \mathrm{MVP}$ will be the first best choice. Q1 group is better in terms of Alpha and Sharpe ratio. This kind of investment has one more advantage. It is easier to form it. Investors simply rank the market-cap top 200 stocks by historical standard deviations and choose 40 lowest risk stocks every quarter. In the case of minimum variance portfolios, they have to estimate covariance matrices and be able to use an optimizer.

Table 6 | Empirical Characteristics of Volatility Quintiles in the Period 2002-2015

\begin{tabular}{|l|c|c|c|c|c|}
\hline & Q1 & Q2 & Q3 & Q4 & Q5 \\
\hline Average Returns & $0.98 \%$ & $1.18 \%$ & $1.10 \%$ & $1.08 \%$ & $0.64 \%$ \\
\hline $\begin{array}{l}\text { Geometric Average } \\
\text { Returns }\end{array}$ & $0.94 \%$ & $1.10 \%$ & $0.99 \%$ & $0.92 \%$ & $0.44 \%$ \\
\hline Standard Deviation & $2.71 \%$ & $3.89 \%$ & $4.70 \%$ & $5.52 \%$ & $6.22 \%$ \\
\hline Beta (CDAX) & 0.355 & 0.536 & 0.686 & 0.828 & 0.886 \\
\hline Sharpe Ratio & 0.304 & 0.264 & 0.202 & 0.168 & 0.078 \\
\hline Alpha (CDAX) & $0.61 \%$ & $0.70 \%$ & $0.53 \%$ & $0.42 \%$ & $-0.05 \%$ \\
\hline Alpha (t-stat.) & $4.404^{* * *}$ & $3.903^{* * *}$ & $2.856^{* * *}$ & $2.139^{* *}$ & -0.206 \\
\hline Beta (EWP) & 0.549 & 0.848 & 1.041 & 1.221 & 1.344 \\
\hline Alpha (EWP) & $0.36 \%$ & $0.31 \%$ & $0.07 \%$ & $-0.11 \%$ & $-0.65 \%$ \\
\hline Alpha (t-stat.) & $3.472^{* * *}$ & $3.316^{* * *}$ & 0.754 & -0.980 & $-3.954^{* * *}$ \\
\hline Cumulative Returns & $328.87 \%$ & $449.55 \%$ & $363.49 \%$ & $319.13 \%$ & $97.90 \%$ \\
\hline
\end{tabular}

Note: Alpha (t-stat.) is the t-statistic $\left({ }^{* *},{ }^{* *},{ }^{*}\right.$ denote rejection of the null at the $1 \%, 5 \%$ and $10 \%$ level of significance)

Source: Own analysis.

Figure 6 presents cumulative returns of quintiles and their characteristics in the riskreturn space. The structure of the risk-return profile is very similar as showed in Clarke, de Silva and Thorley (2013). The lowest volatility stocks quintile is not the best performer, but it has the higher returns than the high risk stocks group. The difference in annualized compound returns between low and high risk stocks is $6 \%$ !

We next calculate cumulative weights of each volatility quintile in the top 200 MVP (see Figure 7). On average, $67 \%$ of the top $200 \mathrm{MVP}$ is formed by stocks from the lowest volatility sort. If we consider Q1 and Q2 groups as low volatility stocks, the average allocation of the top $200 \mathrm{MVP}$ in these securities is $83 \%$ ! The average investment in the high risk stocks (Q4 and Q5) is only $8.5 \%$. Thus, the minimum variance portfolio is strongly exposed to low volatility equities. According to Scherer's text, performances of minimum variance portfolios seem to be related to pricing anomalies. 

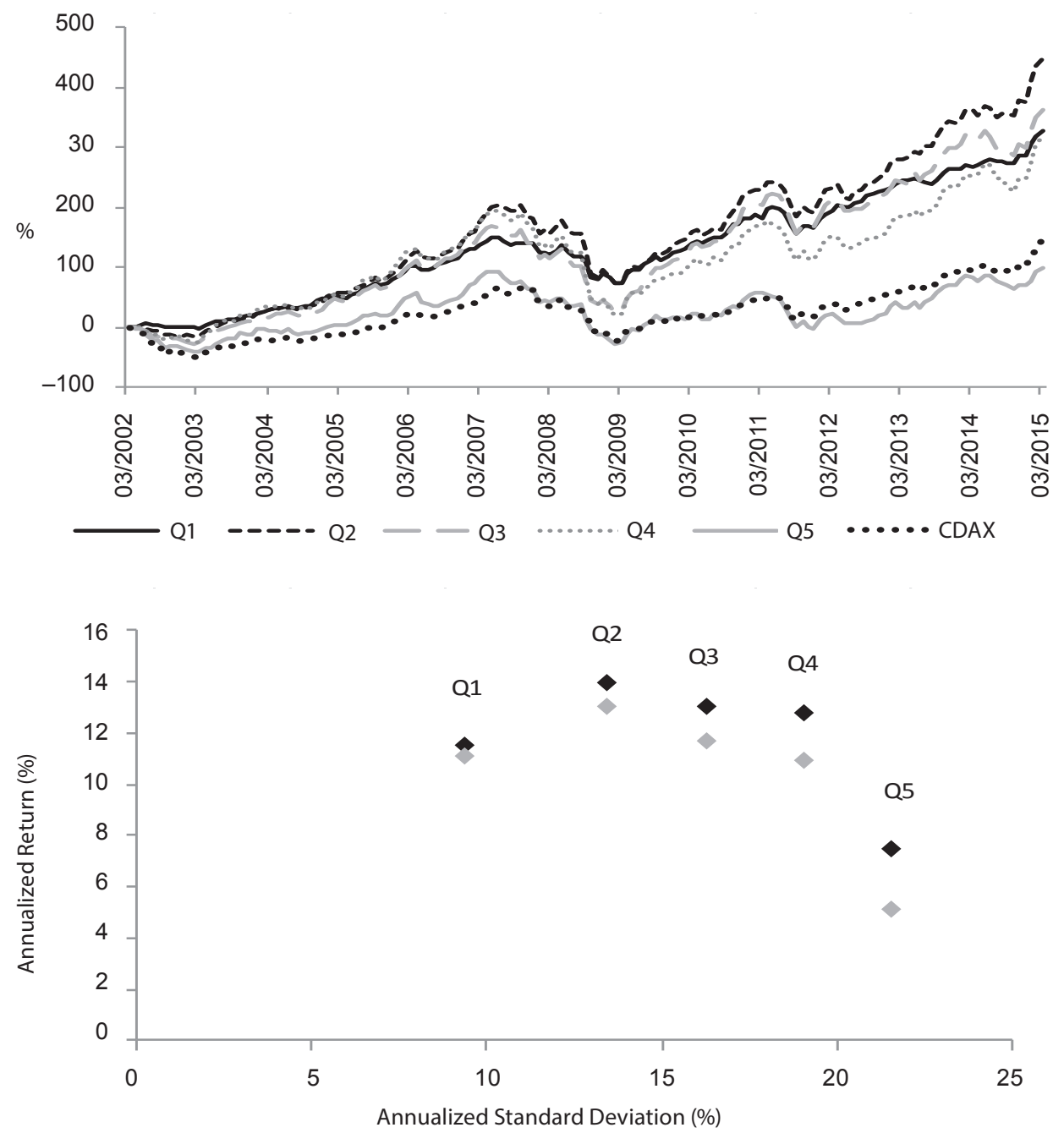

Average Return

Compound Return

Source: Own analysis.

To be correct, it is useful to provide a warning about results presented in the text above. We do not incorporate fees for stock trading and bid-ask spreads, which reduce portfolio profits. Risk adjusted performance results are statistically significant, but one can consider the analysed period as a high volatility environment for equity investing. That should not be surprising that minimum variance portfolios generate large and positive alphas in this environment; and the period studied is 13 years, which is a short period in comparison with cited articles (cited texts reported similar results on other developed markets in a timehorizon of 40 years). 


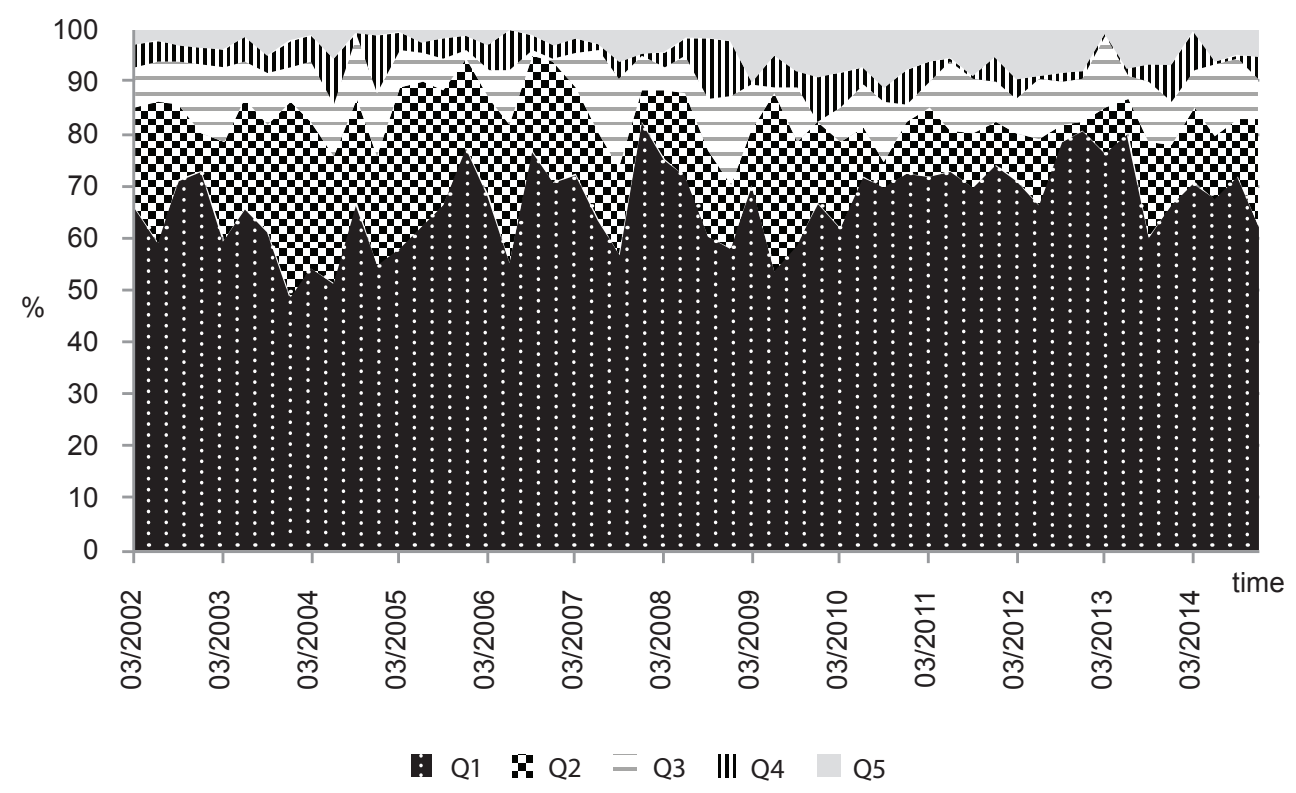

Source: Own analysis.

It seems that the CDAX index is an inefficient investment opportunity in the riskreturn world in the period 2002-2015. The CDAX index is more risky than our minimum variance portfolios and thus one should expect a higher rate of return for this opportunity. The CDAX's yield is lower. This fact simply contradicts the core of finance. On the other hand, we can expect a higher loss in bad time periods.

Cited texts show that market-cap weighted indices on other developed markets are also inefficient. Their results are more robust due to longer periods studied. So, let us pose the question: Why are market-cap weighted portfolios considered as market portfolio proxies? According to the basic portfolio theory, a market portfolio lies on the efficient frontier. Empirical works show us that is not the case for market-cap weighted portfolios (indices). They are dominated by other investment opportunities. Financial institutions investing in stocks also use market-cap indices as benchmarks (see Baker, Bradley and Wurgler, 2011) and try to track them. Thus, the result is the fact that their portfolios are inefficient and dominated. The objective of those institutional investors is to minimize the tracking error instead of optimize the risk-return profile using the available stock universe. It is correct to point out that a minimum variance portfolio is not a market portfolio proxy, but it can offer better risk-return characteristics than market-cap weighted alternatives in the longrun period. Perhaps it is time to think about reducing weights of market-cap weighted indices in benchmarks in favour of minimum variance portfolios, or at least invest a small part of equity funds in the minimum variance strategy. Scherer (2010) even claims that investors search for new alternatives in index definition. The minimum variance approach is a potential solution for these new passive concepts. 


\section{Conclusion}

We studied minimum variance portfolios and their characteristics on the German stock market in the period 2002-2015. Those investment opportunities had both lower risk and the same or higher returns than the market-cap weighted CDAX index. Properties reported above are similar to other developed equity markets.

In general, the minimum variance portfolio concept seems to be alive and applicable. Financial literature has presented better results of this strategy in comparison with the traditional market-cap weighted approach. Some practitioners have already launched new ETFs based on the minimum variance theory on developed equity markets. Thus, the strategy also starts to be available to retail investors.

\section{References}

Ang, A., Hodrick, R. J., Xing, Y., Zhang, X. (2006). The Cross-Section of Volatility and Expected Returns. The Journal of Finance, 61 (1), 259-299, http://dx.doi.org/10.1111/j.15406261.2006.00836.x

Ang, A., Hodrick, R. J., Xing, Y., Zhang, X. (2009). High Idiosyncratic Volatility and Low Returns: International and Further U.S. Evidence. The Journal of Financial Economics, 91(1), 1-23, http://dx.doi.org/10.1016/j.jfineco.2007.12.005

Baker, M., Bradley, B., Wurgler, J. (2011). Benchmarks as Limits to Arbitrage: Understanding the Low-Volatility Anomaly. Financial Analysts Journal, 67(1), 40-54, http://dx.doi.org/10.2469/faj.v67.n1.4

Baker, N. L., Haugen, R. A. (2012). Low Risk Stocks Outperform within All Observable Markets of the World. Social Science Research Network. [Retrieved 2013-6-13] Available at: http://ssrn.com/abstract=2055431

Blitz, D. C., van Vliet, P. (2007). The Volatility Effect: Lower Risk without Lower Return. Journal of Portfolio Management, 34(1), 102-113, http://dx.doi.org/10.3905/jpm.2007.698039

Clarke, R. G., De Silva, H., Thorley, S. (2006). Minimum Variance Portfolios in the U.S. Equity Market. Journal of Portfolio Management, 33(1), 10-24, http://dx.doi.org/10.3905/jpm.2006.661366

Clarke, R. G., De Silva, H., Thorley, S. (2011). Minimum-Variance Portfolio Composition. Journal of Portfolio Management, 37(2), 31-45, http://dx.doi.org/10.3905/jpm.2011.37.2.031

Clarke, R. G., De Silva, H., Thorley, S. (2013). Risk Parity, Maximum Diversification, and Minimum Variance: An Analytic Perspective. Journal of Portfolio Management, 39(3), 39-53, http://dx.doi.org/10.3905/jpm.2013.39.3.039

DeMiguel, V., Garlappi, L., Uppal, R. (2007). Optimal versus Naive Diversification: How Inefficient is the 1/N Portfolio Strategy? The Review of Financial Studies, 22(5), 1915-1953, http://dx.doi.org/ 10.1093/rfs/hhm075

Fama, E. F., French, K. R. (1992). The Cross-Section of Expected Stock Returns. The Journal of Finance, 47(2), 427-465. DOI: 10.1111/j.1540-6261.1992.tb04398.x.

Fama, E. F., French, K. R. (1996). Multifactor Explanations of Asset Pricing Anomalies. The Journal of Finance, 51(1), 55-84, http://dx.doi.org/10.1111/j.1540-6261.1996.tb05202.x

Haugen, R., Baker, N. (1991). The Efficient Market Inefficiency of Capitalization-Weighted Stock Portfolios. Journal of Portfolio Management, 17(3), 35-40, http://dx.doi.org/10.3905/ jpm.1991.409335 
Jagannathan, R., Ma, T. (2003). Why Imposing the Wrong Constraints Helps. The Journal of Finance, 58(4), 1651-1683, http://dx.doi.org/10.1111/1540-6261.00580

Jensen, M. C. (1968). The Performance of Mutual Funds in the Period 1945-1964.

The Journal of Finance, 23(2), 389-416, http://dx.doi.org/10.1111/j.1540-6261.1968.tb00815.x

Markowitz, H. (1952). Portfolio Selection. The Journal of Finance, 7(1), 77-91, http://dx.doi.org/10.1111/j.1540-6261.1952.tb01525.x

Musílek, P., Jeřábek, T. (2015). Hedgeové fondy a akciové trhy. Politická ekonomie, 63(1), 91-107, http://dx.doi.org/10.18267/j.polek.990

Scherer, B. (2010). A New Look at Minimum Variance Investing. Social Science Research Network. [Retrieved 2014-12-15] Available at: http://ssrn.com/abstract=1681306

Sharpe, W. F. (1964). Capital Asset Prices: A Theory of Market Equilibrium under Conditions of Risk. The Journal of Finance, 19(3), 425-442, http://dx.doi.org/10.2307/2977928

Tobin, J. (1958). Liquidity Preference as Behavior towards Risk. The Review of Economic Studies, 25(2), 65-86, http://dx.doi.org/10.2307/2296205 